\title{
Influence of maternal hyperthyroidism in the rat on the expression of neuronal and astrocytic cytoskeletal proteins in fetal brain
}

\author{
I M Evans, M R Pickard, A K Sinha, A J Leonard, D C Sampson \\ and $\mathbf{R} \mathbf{P}$ Ekins
}

Division of Molecular Endocrinology, University College London Medical School, Mortimer Street, London W1N 8AA, UK

(Requests for offprints should be addressed to A K Sinha; Email: arun.sinha@ucl.ac.uk)

\begin{abstract}
Maternal hypothyroidism during pregnancy impairs brain function in human and rat offspring, but little is known regarding the influence of maternal hyperthyroidism on neurodevelopment. We have previously shown that the expression of neuronal and glial differentiation markers in fetal brain is compromised in hypothyroid rat dam pregnancies and have now therefore extended this investigation to hyperthyroid rat dams. Study groups comprised partially thyroidectomised dams, implanted with osmotic pumps infusing either vehicle (TX dams) or a supraphysiological dose of thyroxine (T4) (HYPER dams), and euthyroid dams infused with vehicle ( $\mathrm{N}$ dams). Cytoskeletal protein abundance was determined in fetal brain at 21 days of gestation by immunoblot analysis. Relative to $\mathrm{N}$ dams, circulating total T4 levels were reduced to around one-third in TX dams but were doubled in HYPER
\end{abstract}

dams. Fetal brain weight was increased in HYPER dams, whereas litter size and fetal body weight were reduced in TX dams. Glial fibrillary acidic protein expression was similar in HYPER and TX dams, being reduced in both cases relative to $\mathrm{N}$ dams. $\alpha$-Internexin (INX) abundance was reduced in HYPER dams and increased in TX dams, whereas neurofilament 68 (NF68) exhibited increased abundance in HYPER dams. Furthermore, INX was inversely related to - and NF68 directly related to maternal serum total T4 levels, independently of fetal brain weight. In conclusion, maternal hyperthyroidism compromises the expression of neuronal cytoskeletal proteins in late fetal brain, suggestive of a pattern of accelerated neuronal differentiation.

Journal of Endocrinology (2002) 175, 597-604

\section{Introduction}

In humans and rats, maternal thyroid hormone (TH), predominantly thyroxine (T4), is transferred to the fetus from before the onset of fetal thyroid function. Transferred T4 accumulates in the fetal brain, and is deiodinated to bioactive 3,5,3'-tri-iodothyronine (T3) (Morreale de Escobar et al. 1997, Pickard et al. 1997). T3 nuclear receptors (TR) are expressed in early fetal brain, therefore maternal TH may regulate fetal brain development (Morreale de Escobar et al. 1997, Pickard et al. 1997). Indeed, children born to hypothyroxinaemic mothers in iodine-deficiency endemias are at increased risk of a spectrum of neurological disorders. Such damage appears to be sustained in the first trimester of pregnancy, before the onset of fetal TH secretion (Connolly \& Pharoah 1989, Morreale de Escobar et. al. 1997), and measures of cognitive and motor function in offspring correlate with maternal serum total and free T4 levels. In iodine-replete environments, cognitive and motor development is also impaired in offspring of women with moderate hypothyroidism (Man et al. 1991, Haddow et al. 1999) or even low-normal serum free T4 levels (Pop et al. 1999). Furthermore, psychomotor test scores of infants are directly related to first trimester maternal serum free $\mathrm{T} 4$ levels (Pop et al. 1999).

In the rat, moderate maternal hypothyroidism also results in deficient locomotor and learning behaviour in the progeny (Attree et al. 1992, Porterfield \& Hendrich 1993), and brain development is disrupted from before the onset of fetal thyroid function (Pickard et al. 1993, 1999). Early neuronal maturation, in particular, appears compromised (Evans et al. 1999, Sampson et al. 2000), with some deficits persisting in postnatal life (Porterfield \& Hendrich 1991, Pickard et al. 1997, Evans et al. 1999).

Most studies on the influence of the maternal thyroid on fetal development have centered on hypofunction, mainly because this condition is more commonly encountered during pregnancy than hyperfunction. Nevertheless, maternal hyperthyroidism is a significant endocrinological disorder in pregnancy; the prevalence of thyrotoxicosis (predominantly Graves' disease) being 0.05-0.2, with a further 3\% of mothers exhibiting gestational transient thyrotoxicosis (Burrow 1993, Glinoer 1997). Maternal TH 
excess during pregnancy results in an increased incidence of pre-eclampsia and low birth weight, the latter being due to premature delivery (Millar et al. 1994), but little is known regarding its effects on neurodevelopment. Two early studies independently reported a high incidence of hyperthyroidism in mothers of schizophrenics (Pollin et al. 1966, MacSweeney et al. 1978); however, these findings remain to be confirmed.

In rats, chronic maternal hyperthyroidism stimulates feto-placental and neonatal growth (Spencer \& Robinson 1993), but its effects on fetal brain have not been studied. Induction of maternal hyperthyroidism during late pregnancy also increases fetal body weight, but fetal brain growth and cerebellar development appear normal (Schwartz et al. 1997). Nevertheless, the expression of several neuronal genes (neuroendocrine-specific protein and Oct1) in fetal cerebral cortex are sensitive to acute maternal T4 administration during late gestation (Dowling et al. 2000).

There is evidence to suggest that TH regulates specific markers of neuronal and glial differentiation, such as neurofilament-68 (NF68) and glial fibrillary acidic protein (GFAP), in both in vivo and in vitro models of congenital hypothyroidism (Gould et al. 1990, Lima et al. 1997, Ghosh et al. 1999, Rahamam et al. 2000). Recently, we have shown that maternal hypothyroidism can also disturb the ontogeny of these proteins in fetal brain, as well as that of $\alpha$-internexin (INX) - the earliest appearing neuronal specific intermediate filament (Sampson et al. 2000). In the present study, we have investigated the hypothesis that chronic moderate maternal hyperthyroidism also impairs neuronal and astrocytic differentiation.

\section{Materials and Methods}

\section{Materials}

Alzet osmotic pumps (Model 2004, pumping rate $0.25 \mu \mathrm{l} / \mathrm{h}$ for 28 days) were purchased from Charles River UK (Margate, Kent, UK). Bovine serum albumin (BSA), T4 and monoclonal antibodies to GFAP (clone GA-5), vimentin (clone V9) and NF68 (clone NR-4) were purchased from Sigma-Aldrich Chemical Company (Gillingham, Dorset, UK). Monoclonal antibody to INX (clone 3 G8) was purchased from Chemicon International (Harrow, UK). Western blotting reagents were purchased from Amersham Bioscience (Little Chalfont, Bucks, UK). The total T4 radioimmunoassay (RIA) kit was obtained from Skybio (Wyboston, Beds, UK), the total T3 RIA kit from B M Browne Ltd (Reading, Berks, UK) and the rat thyroid-stimulating hormone (TSH) RIA kit from Biocode Biotechnology (Liege, Belgium).

\section{Animal model}

All animal procedures were performed in accordance with the Animals (Scientific Procedures) Act 1986. Sprague-
Dawley rat dams were partially thyroidectomised by surgery (Evans et al. 1999), allowed to recover for 2 weeks, then subcutaneously implanted posterior to the scapulae with an osmotic minipump, infusing either $1.5 \mu \mathrm{g}$ T4/ $100 \mathrm{~g}$ pre-mating body weight/day (HYPER dams) or vehicle (TX dams). Age-matched normal dams, implanted with pumps infusing vehicle ( $\mathrm{N}$ dams), were also studied. T4 was dissolved in $30 \mathrm{mM} \mathrm{NaOH}$ and, after spectrophotometric verification of the concentration (absorbance at $325 \mathrm{~nm}$ ), diluted in phosphate-buffered saline (PBS; $\mathrm{pH}$ $7 \cdot 4)$ containing $5 \%(\mathrm{w} / \mathrm{v}) \mathrm{BSA}$; vehicle therefore consisted of an equivalent amount of $30 \mathrm{mM} \mathrm{NaOH}$ in PBS/BSA. After a 2-day recovery period, dams were time-mated with normal males. Dams were tail bled for TH determination before osmotic pump implantation and within 3 days after mating. All animals were maintained at $22{ }^{\circ} \mathrm{C}$ on a cycle of $14 \mathrm{~h}$ light: $10 \mathrm{~h}$ darkness, with free access to a standard small laboratory animal diet; the drinking water of TX and HYPER animals was supplemented with $0 \cdot 1 \%$ (w/v) calcium lactate. At 21 days of gestation (dg), pregnant dams were stunned and killed by cervical dislocation, and a cardiac blood sample was taken for serum $\mathrm{TH}$ assay. Uterine horns containing feto-placental units were removed to ice and maternal carcass weight was determined. Feto-placental tissues were dissected on ice, weighed, snap-frozen on dry ice then stored at $-20^{\circ} \mathrm{C}$.

\section{Sample preparation and Western blotting}

Whole fetal brains were pooled from each pregnancy $(n \geq$ three brains/pool), homogenised in 9 vol ice-cold TE buffer (2 mM EDTA, 0.5\% (v/v) Triton X-100 and $10 \mathrm{mM}$ phenylmethylsulphonylfluoride in $50 \mathrm{mM}$ Tris$\mathrm{HCl} ; \mathrm{pH}$ 6.8) and subjected to Western blot analysis (Sampson et al. 2000). Briefly, fetal brain homogenates from N, HYPER and TX dams were electrophoresed side-by-side on SDS-PAGE gels along with the appropriate standard $(2.5 \mu \mathrm{g}$ protein from normal $16 \mathrm{dg}$ fetal brain for vimentin; $0.25,0.5$ and $2.5 \mu \mathrm{g}$ protein from normal adult brain for GFAP, NF68 and INX respectively) and molecular weight markers, blotted onto nitrocellulose membranes and probed with specific monoclonal antibodies. Detection was via a horseradish peroxidase-linked secondary antibody and ECL reagents (Amersham, following the manufacturer's protocol). Autoradiographic images were digitised and signals analysed using NIH Image 6.1 (US National Institutes of Health; http://rsb.info.gov/ nih-image/). Sample signals were expressed relative to the appropriate filter standard to correct for filter-to-filter variation.

\section{Determination of maternal thyroid status}

TSH, total T3 and total T4 levels were determined in maternal serum by RIA, according to the manufacturers' protocols. The T3 antibody does not cross react with any 
major analogues of T3. The T4 antibody exhibits cross reactivity of less than $2.5 \%$ with $\mathrm{T} 3$ and $30 \%$ with reverse T3 in molar \% terms.

\section{Determination of DNA and protein}

DNA was determined by a fluorimetric method (Labarca \& Paigen 1980), and protein by Coomassie dye-binding (Bradford 1976).

\section{Statistical analysis}

All values are means \pm S.E.M. Statistical significance $(P<0 \cdot 05)$ was determined by analysis of variance (ANOVA) with post-hoc analysis by Fisher's PLSD test. Where necessary, data were transformed prior to analysis to satisfy the criteria for ANOVA. Linear and non-linear regression analyses were performed as appropriate, with a runs test to determine data linearity. Statistical analyses were performed using Statview 1.03 (Abacus Concepts, Inc., Berkeley, CA, USA) and GraphPad Prism 2.0c (GraphPad Software, Inc., San Diego, CA, USA).

\section{Results}

\section{Maternal thyroid status}

Serum total T4 levels in HYPER dams during early gestation $(0-3 \mathrm{dg})$ were more than double those in $\mathrm{N}$ dams, whereas they were reduced in TX dams to approximately one-third of those in $\mathrm{N}$ dams (Table 1). These relationships were maintained at $21 \mathrm{dg}$. Serum total T3 levels were also increased in HYPER dams but only during early gestation, whereas they were normal in TX dams at all stages of pregnancy (Table 1). In early pregnancy, serum TSH was undetectable in HYPER dams and was markedly increased in TX dams relative to $\mathrm{N}$ dams (Table 1). Near term, however, serum TSH levels were normal in HYPER dams but remained elevated in TX dams.

\section{Reproductive performance and feto-placental growth}

At $21 \mathrm{dg}$, maternal carcass weight was equivalent in HYPER dams $(354.8 \pm 11 \cdot 3 \mathrm{~g} ; n=6), \quad$ TX dams $(340 \cdot 5 \pm 10 \cdot 4 \mathrm{~g} ; n=4)$ and $\mathrm{N}$ dams $(357 \cdot 9 \pm 20 \cdot 4 \mathrm{~g} ; n=6)$. Litter size and fetal body weight were also normal in HYPER dams, whereas these parameters were reduced in TX dams (Table 1), as expected (Sampson et al. 2000). In contrast, fetal brain weight was slightly elevated (by 9\%) in HYPER dams relative to $\mathrm{N}$ dams, but normal in TX dams (Table 1). Fetal brain weight exhibited a linear relationship with the maternal serum T4 level at $21 \mathrm{dg}$ $(r=0.65, \quad P<0.01)$ or during early gestation $(r=0.71$, $P<0 \cdot 005$ ). Weights of the placenta (whole, and after

www.endocrinology.org

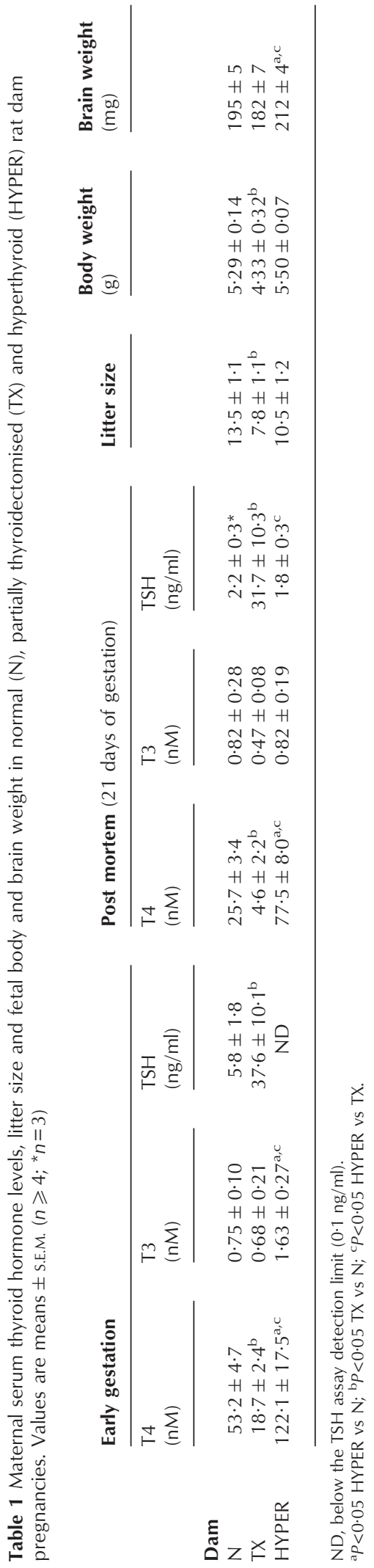

Journal of Endocrinology (2002) 175, 597-604 


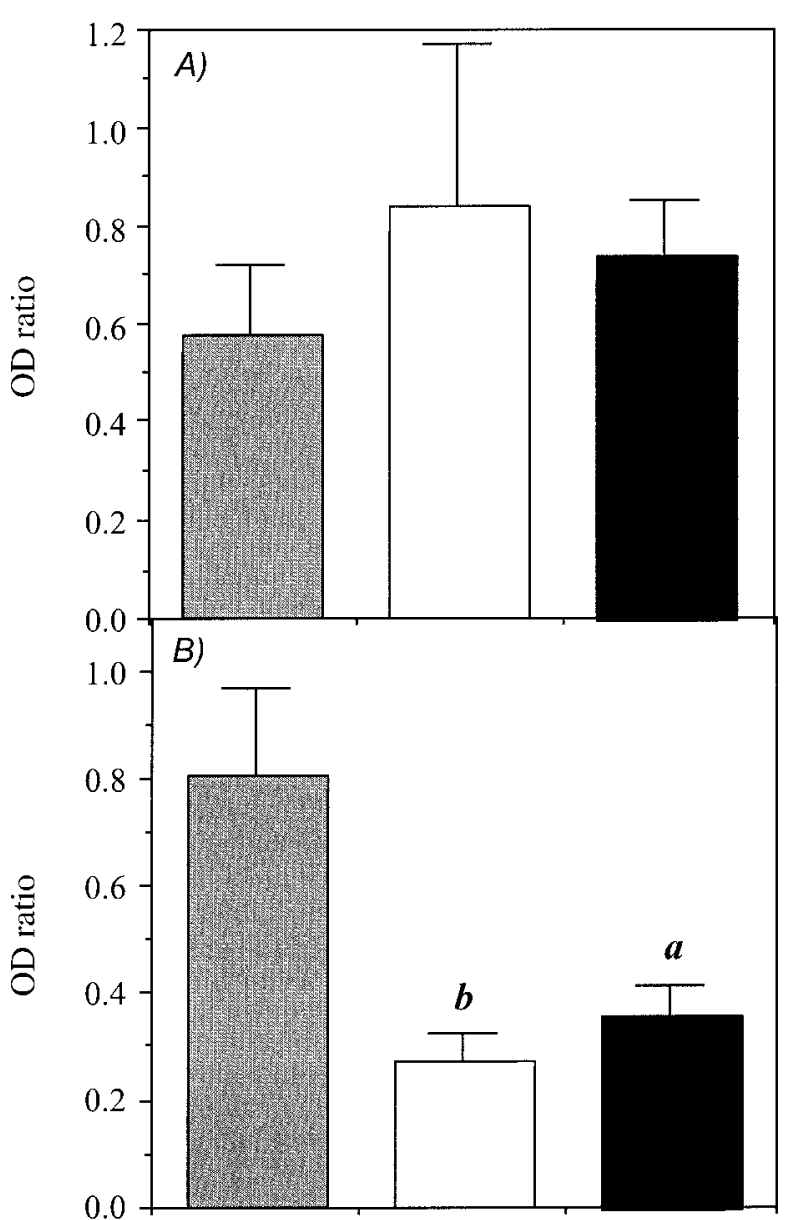

Figure 1 Maternal thyroid status and vimentin and GFAP expression in fetal brain. Protein abundance of $(A)$ vimentin and $(B)$ GFAP in $21 \mathrm{dg}$ fetal brain from $\mathrm{N}$ (shaded bars), TX (open bars) and HYPER (solid bars) dam pregnancies. Values are means \pm S.E.M. $(n \geq 4) .{ }^{a} P<0.05$ HYPER vs $N ;{ }^{b} P<0.05$ TX vs $N$.

dissection into maternal and fetal sides) and fetal liver, lung and heart were normal in HYPER and TX dams (data not shown). Fetal brain protein and DNA concentrations and protein:DNA ratios were also normal in HYPER and TX dams (data not shown).

\section{Cytoskeletal protein abundance in fetal brain}

All antibodies specifically recognised protein species of the expected size, as previously reported (Sampson et al. 2000). The abundance of vimentin, an intermediate filament protein which is expressed mainly in neural precursor cells in fetal brain, was similar in HYPER, TX and $\mathrm{N}$ dams (Fig. 1A). In contrast, GFAP, which is the predominant intermediate filament protein of mature astrocytes, exhibited decreased abundance in HYPER dams (by 49\%) and in TX dams (by 62\%) relative to $\mathrm{N}$ dams (Fig. $1 B$ ).

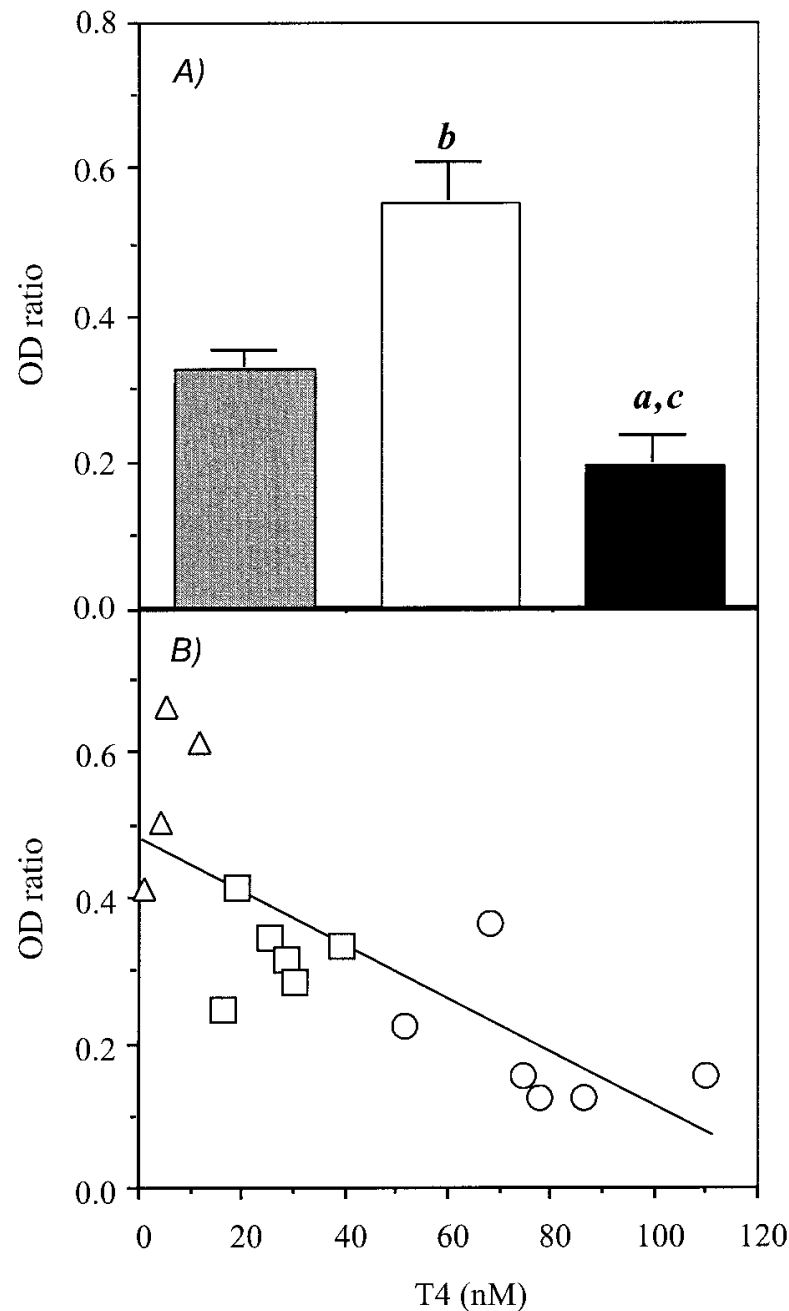

Figure 2 Maternal thyroid status and INX expression in fetal brain. (A) Protein abundance of INX in $21 \mathrm{dg}$ fetal brain from $\mathrm{N}$ (shaded bars), TX (open bars) and HYPER (solid bars) dam pregnancies. Values are means \pm S.E.M. $(n \geq 4) .{ }^{a} P<0.05$ HYPER vs $N ;{ }^{b} P<0.05$ TX vs $N$; ${ }^{c} P<0.05$ HYPER vs TX. $(B)$ Regression of INX protein abundance in fetal brain from $N(\square)$, TX $(\triangle)$ and HYPER $(O)$ dams, against maternal serum total T4 at $21 \mathrm{dg}(r=-0 \cdot 78$, $P<0 \cdot 001)$.

The expression of two markers of early neuronal differentiation was also studied: INX, an axonal type IV intermediate filament protein, which is expressed in newly differentiating neurons, and NF68, the low molecular weight neurofilament triplet protein, which is expressed subsequent to INX. The abundance of INX was reduced (by 40\%) in HYPER dams, but increased (by 69\%) in TX dams, when compared with $\mathrm{N}$ dams (Fig. 2A). Upon combining data from all three animal groups, INX protein abundance was found to be inversely related to maternal serum T4 at $21 \mathrm{dg}(r=-0.78, P<0.001$; Fig. $2 B)$ or during early gestation $(r=-0 \cdot 79, P<0 \cdot 001)$. In contrast, 


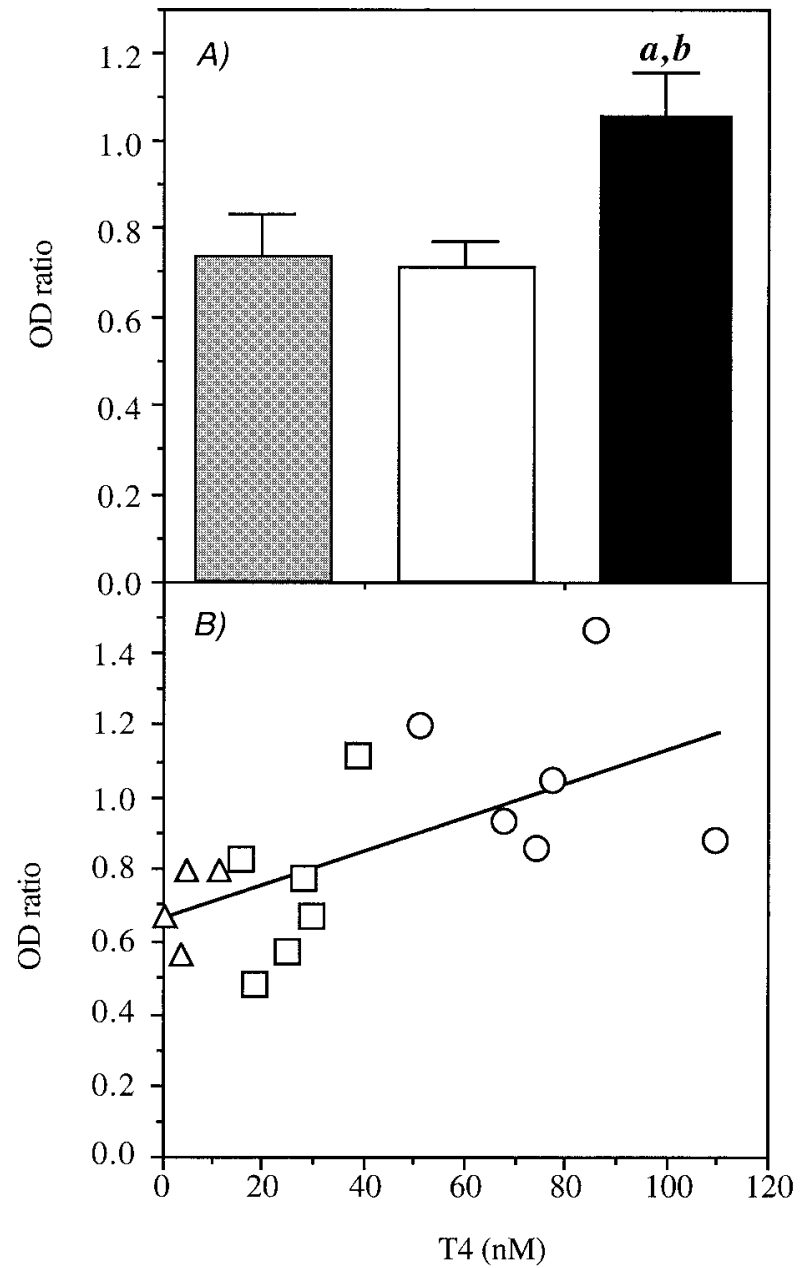

Figure 3 Maternal thyroid status and NF68 expression in fetal brain. (A) Protein abundance of NF68 in $21 \mathrm{dg}$ fetal brain from $\mathrm{N}$ (shaded bars), TX (open bars) and HYPER (solid bars) dam pregnancies. Values are means \pm S.E.M. $(n \geq 4) .{ }^{a} P<0.05$ HYPER vs $\mathrm{N} ;{ }^{b} P<0.05$ HYPER vs TX. (B) Regression of NF68 protein abundance in fetal brain from $\mathrm{N}(\square), \mathrm{TX}(\triangle)$ and HYPER $(\bigcirc)$ dams, against maternal serum total T4 at $21 \mathrm{dg}(r=0 \cdot 61, P<0 \cdot 05)$.

the abundance of NF68 was elevated (by 44\%) in HYPER dams but unchanged in TX dams relative to $\mathrm{N}$ dams (Fig. $3 A$ ). Furthermore, NF68 abundance in the combined data set was directly related to maternal serum $\mathrm{T} 4$ at $21 \mathrm{dg}$ $(r=0.61, P<0.05$; Fig. $3 B)$ or during early gestation $(r=0 \cdot 78, P<0 \cdot 001)$.

In fetal brain from $\mathrm{N}$ dams, protein abundance of GFAP and NF68 increases during late gestation whereas that of INX declines (Sampson et al. 2000). Near term fetal brain weight is increased in HYPER dams, so that the changes in INX and NF68 abundance may occur secondary to enhanced fetal brain growth. Indeed in the combined data, INX abundance was inversely related to fetal brain weight $(r=-0.65, \quad P=0 \cdot 007)$, and NF68 abundance tended towards a direct relationship $(r=0.44, P=0 \cdot 091)$. This potentially confounding effect of fetal brain weight was further examined by multiple regression analysis. Regression of INX abundance on fetal brain weight and maternal serum total $\mathrm{T} 4$, either at $21 \mathrm{dg}$ or during early gestation, yielded similar significant relationships (multiple regression coefficient $R=0.801$ and 0.795 respectively, $P<0 \cdot 002$; $n=16)$. In both models, however, INX was related only to maternal serum T4 $(P<0 \cdot 020)$ and not to fetal brain weight. Regression of NF68 on fetal brain weight and maternal serum T4 also gave significant relationships, albeit this relationship was stronger in the model with early gestation T4 levels $(R=0.794, P=0.002 ; n=16)$ than in the model with T4 levels at $21 \mathrm{dg}(R=0 \cdot 616, P=0 \cdot 045$; $n=16$ ). Indeed, whereas the NF68 was related to early gestation maternal serum T4 $(P=0 \cdot 014)$, it only tended towards a significant relationship with maternal serum T4 at $21 \mathrm{dg}(P=0 \cdot 068)$. Nevertheless, NF68 abundance was unrelated to brain weight in both models.

\section{Discussion}

We postulated that chronic maternal hyperthyroidism disrupts fetal brain development and developed a rat dam model to test this hypothesis. The rat placenta is only a limited barrier to the transfer of maternal T4 and T3 (Calvo et al. 1992), but the fetal brain is dependent upon local deiodination of T4 for its T3 supply (Ruiz de Ona et al. 1988). Consequently T4 was used to induce maternal hyperthyroidism in the model. This was administered by continuous infusion to avoid wide fluctuations in circulating maternal T4 levels resulting from daily injection regimes (Spencer \& Robinson 1993). Infusion of T4 into TX dams increased circulating maternal T4 levels to more than double those of $\mathrm{N}$ dams throughout pregnancy; maternal serum T3 levels were also increased, but only during early gestation $(0-3 \mathrm{dg})$. Furthermore, maternal serum TSH levels in HYPER dams were undetectable in early gestation, and depressed relative to TX dams alone at $21 \mathrm{dg}$. Thus HYPER dams were moderately hyperthyroid during early gestation but hyperthyroxinaemic during late gestation. The latter findings agree with previous studies of hypothyroid rat dams infused with $\mathrm{T} 4$ during late gestation (Calvo et al. 1990, 1992). However, a similar T4 dose to the one used in the present study was only sufficient to normalize circulating total $\mathrm{T} 4$ levels in the previous studies. A possible explanation for this discrepancy may be that the dams receiving $\mathrm{T} 4$ in the previous studies were made hypothyroid by methimazole (MMI) administration, whereas those in the current study were surgically thyroidectomised. MMI increases thyroidal type I deiodinase activity (Erickson et al. 1982) and may therefore facilitate clearance of circulating T4. In addition, removal of the majority of the thyroid gland is likely to disturb $\mathrm{TH}$ homeostatic mechanisms. Indeed, in preliminary 
experiments, an equivalent dose of $\mathrm{T} 4$ infused into $\mathrm{N}$ dams failed to consistently increase circulating total T4 levels to the same degree.

Infusion of T4 prevented the reductions in litter size and fetal body weight seen in TX dams near term, these parameters being unchanged in HYPER dams relative to $\mathrm{N}$ dams. More severe, chronic maternal hyperthyroidism is also without effect on litter size, but increases fetoplacental weight near term (Spencer \& Robinson 1993). Similarly, T4 given during late gestation stimulates fetal growth in severe (Schwartz et al. 1997), but not moderate, hyperthyroidism (Calvo et al. 1992, Morreale de Escobar et al. 1993). Thus it appears that only severe maternal hyperthyroidism influences general feto-placental growth. In the current study, fetal brain weight was marginally higher in HYPER dams relative to $\mathrm{N}$ and TX dams, but the weights of other fetal tissues examined were normal, suggesting that maternal hyperthyroidism may have selective effects on the central nervous system. In contrast, severe maternal hyperthyroidism induced from $15 \mathrm{dg}$ has no effect on fetal brain weight, even though it increases fetal body weight (Schwartz et al. 1997). A critical period may therefore exist during early gestation when brain growth is specifically sensitive to maternal hyperthyroidism.

The main finding was that moderate maternal hyperthyroidism resulted in abnormal expression of neuronal cytoskeletal proteins in fetal brain near term. Thus, the abundance of INX was decreased, whereas that of NF68 was increased in HYPER dams relative to $\mathrm{N}$ and TX dams. In TX dams, INX abundance was increased relative to $\mathrm{N}$ dams, as expected (Sampson et al. 2000). However, NF68 abundance in TX dams was unchanged in the present study, whereas it was reduced in the earlier study (Sampson et al. 2000). This discrepancy may be due to the more severe degree of maternal hypothyroidism in the earlier study (pre-mating maternal serum total T4 levels in TX dams were around half those in the present study), which was sufficient to retard fetal brain growth near term (Sampson et al. 2000). In this regard, regression analysis of the combined N, TX and HYPER dam data revealed that NF68 protein abundance was directly related to - and INX protein abundance was inversely related to maternal serum T4 levels, with INX exhibiting a greater dependency than NF68 on maternal serum T4. Importantly, these relationships were independent of the more general effects of maternal thyroid status on fetal brain growth. Since the abundance of INX declined and that of NF68 increased during late fetal brain development, these findings indicated that maternal hypothyroidism delays, whereas maternal hyperthyroidism accelerates, neuronal maturation.

$\mathrm{TH}$ action in the developing brain is thought to be mediated via TR-dependent regulation of target gene transcription (Koibuchi \& Chin 2000). INX and NF68 are unlikely to be primary targets for maternal $\mathrm{TH}$ action however, since severe maternal hypothyroidism has no effect on their transcript levels in fetal brain, even prior to the onset of fetal thyroid function (Sampson et al. 2001). Nevertheless, T3 acutely stimulates INX protein expression in primary cultures of early differentiating rat neurons (Sampson et al. 2002), and maternal hypothyroidism reduces INX protein abundance in fetal brain prior to the onset of fetal thyroid function (Sampson et al. 2000), supporting a regulatory role for maternal $\mathrm{TH}$ in early neuronal development. From around $17 \mathrm{dg}$, however, the fetal brain can maintain its intracellular T3 level despite wide fluctuations in maternal T4 levels (Morreale de Escobar et al. 1992). Thus, this direct action on INX abundance by T3 is not likely to be the cause of the changes reported here. Rather, they may reflect chronic alterations in the timing of neuronal differentiation sustained during early gestation. This is supported by the divergent effects of severe maternal hypothyroidism on INX and NF68 abundance before and after the onset of fetal TH synthesis (Sampson et al. 2000). Moreover, this postulate may explain why NF68 and INX abundance in late fetal brain exhibit linear relationships with maternal serum T4, despite the operation of brain T3 homeostatic mechanisms.

Earlier work has shown that maternal hypothyroidism reduces GFAP protein in fetal brain in late gestation (Sampson et al. 2000). Present results agree with this finding; however, GFAP abundance in HYPER and TX dams was reduced by a similar extent when compared with $\mathrm{N}$ dams. This is in contrast to in vivo and in vitro models of congenital hypothyroidism in which T3 induces brain GFAP expression in an age- and region-specifc manner (Gould et al. 1990, Lima et al. 1997). Another study, however, found that T3 treatment of astroglial primary culture from mouse neocortex and cerebellum decreased GFAP expression (Andres-Barquin et al. 1994). Thus, in our studies of whole brain, it is possible that regions with increased GFAP expression have been masked by others with quantitatively larger decreases. In addition, the previous studies were reporting a direct effect of T3 on GFAP expression. For reasons discussed earlier, the changes in GFAP expression in the current study are likely to represent an indirect effect arising from an earlier insult - and this may also account for the discrepancies. Another alternative is that the T4 infusion is unable to prevent GFAP compromise in TX dams. Further work is therefore required to determine whether normalisation of circulatory T4 levels in TX dams can prevent the disturbance of fetal brain GFAP protein expression.

Thus, while maternal hypothyroidism tends to delay, in general, neural cell differentiation, the effects of maternal hyperthyroidism are more complex - neuronal and glial differentiation are accelerated and delayed respectively. Given the importance of neuronal-glial interactions for the establishment of vital neural connections, this discordant response to maternal hyperthyroidism is potentially more 
damaging to brain development than a general delay or acceleration. Studies using postnatal progeny of hyperthyroid dams are needed, however, to assess the long-term consequences of this disruption. As well as being markers of neuronal differentiation, both INX and NF68 are thought to be involved in the maintenance and stability of neuronal axons (Kirkpatrick \& Brady 1999). The role of GFAP is less clear, although it has been implicated in neuronal-glial interactions (McCall et al. 1996). Thus alterations in the levels of these proteins per se may result in disturbed neuron-neuron and neuron-glia connectivity; whether the changes reported in the current study are sufficient to cause these effects is, however, unknown and requires investigation by immunohistological studies.

Several important differences exist between rats and humans which must be taken into account when considering the relevance of these findings for humans: for example, materno-fetal $\mathrm{TH}$ economy and the maturity of the brain at birth (Fukuda et al. 1980, Porterfield \& Hendrich 1993, Glinoer 1997). Nevertheless, in both species, materno-fetal T4 transfer occurs throughout pregnancy, and brain development is comparable prior to the onset of fetal thyroid activity, as are many elements of brain TH metabolism and receptor expression (Porterfield \& Hendrich 1993, Morreale de Escobar et al. 1997). Interestingly, parameters of cognitive and motor function in human offspring exhibit linear relationships with circulating maternal total and free T4 levels during early gestation (Connolly \& Pharoah 1989, Pop et al. 1999). Given the results of the present study, it is possible that maternal TH regulation of neuronal differentiation underlies such relationships. Furthermore, they indicate that even moderate maternal hyperthyroidism is detrimental to brain development. However, these points require detailed clinical investigation.

In conclusion, maternal hyperthyroidism disrupts the expression of neuronal cytoskeletal proteins in late fetal brain. Furthermore, the changes tend to be the converse of those seen in maternal hypothyroidism and are indicative of accelerated neuronal differentiation. Work is in progress to determine the regional localisation of such effects and to further delineate the critical period of dependency of neuronal and astrocytic differentiation on maternal thyroid status.

\section{Acknowledgement}

This work was funded by a grant from Action Research.

\section{References}

Attree EA, Sinha AK, Davy MJ, Pickard MR, Rose FD \& Ekins RP 1992 Effects of maternal hypothyroxinemia on activity, emotional responsiveness and exploratory behaviour in adult rat progeny. Medical Science Research 20 197-199.
Bradford M 1976 A rapid and sensitive method for the quantification of microgram quantities of protein utilizing the principle of protein-dye binding. Analytical Biochemistry 72 248-254.

Burrow G 1993 Thyroid function and hyperfunction during gestation. Endocrine Reviews 14 194-202.

Calvo R, Obregon MJ, Ruiz de Ona C, Escobar del Rey F \& Morreale de Escobar G 1990 Congenital hypothyroidism as studied in rats. Crucial role of maternal thyroxine but not 3,5,3'-triiodothyronine in the protection of the fetal brain. Journal of Clinical Investigation 86 889-899.

Calvo R, Obregon M, Escobar del Rey F \& Morreale de Escobar G 1992 The rat placenta and the transfer of thyroid hormones from the mother to the fetus. Effects of maternal thyroid status. Endocrinology 131 357-365.

Connolly KJ \& Pharoah POD 1989 Iodine deficiency, maternal thyroxine levels in pregnancy and developmental disorders in the children. In Iodine and the Brain, pp 317-331. Eds GR DeLong, J Robbins \& PG Condliffe. New York: Plenum Press.

Dowling ALS, Martz GU, Leonard JL \& Zoeller RT 2000 Acute changes in maternal thyroid hormone induce rapid and transient changes in gene expression in fetal rat brain. Journal of Neuroscience $202255-2265$.

Erickson VJ, Cavalieri RR \& Rosenberg LL 1982 Thyroxine5 -deiodinase of rat thyroid, but not that of liver, is dependent on thyrotropin. Endocrinology 111 434-439.

Evans IM, Sinha AK, Pickard MR, Edwards PR, Leonard AJ \& Ekins RP 1999 Maternal hypothyroxinemia disrupts neurotransmitter metabolic enzymes in developing brain. Journal of Endocrinology 161 273-279.

Fukuda H, Ohshima K, Mori M, Kobayashi I \& Greer MA 1980 Sequential changes in the pituitary-thyroid axis during pregnancy and lactation in the rat. Endocrinology 107 1711-1716.

Ghosh S, Rahaman SO \& Sarkar PK 1999 Regulation of neurofilament gene expression by thyroid hormone in the developing rat brain. NeuroReport 10 2361-2365.

Glinoer D 1997 The regulation of thyroid function in pregnancy: pathways of endocrine adaptation from physiology to pathology. Endocrine Reviews 18 404-433.

Gould E, Frankfurt M, Westlind-Danielsson A \& McEwen BS 1990 Developing forebrain astrocytes are sensitive to thyroid hormone. Glia 3 283-292.

Haddow JE, Palomaki GE, Allan WC, Williams JR, Knight GJ, Gagnon J, O'Heir CE, Mitchell ML, Hermos RJ, Waisbren SE, Faix JD \& Klein RZ 1999 Maternal thyroid deficiency during pregnancy and subsequent neuropsychological development of the child. New England Journal of Medicine 341 549-555.

Kirkpatrick LL \& Brady ST 1999 Cytoskeleton of neurons and glia. In Basic Neurochemistry: Molecular, Cellular and Medical Aspects, edn 6, pp 155-174. Eds GJ Seigel, BW Agranoff, RW Albers, SK Fisher \& MD Uhler. New York: Lippincott-Raven.

Koibuchi N \& Chin WW 2000 Thyroid hormone action and brain development. Trends in Endocrinology and Metabolism 11 123-128.

Labarca C \& Paigen K 1980 A simple, rapid and sensitive DNA assay procedure. Analytical Biochemistry 102 344-352.

Lima FR, Trentin AG, Rosenthal D, Chagas C \& Moura-Neto V 1997 Thyroid hormone induces protein secretion and morphologic changes in astroglial cells with an increase in expression of glial fibrillary acidic protein. Journal of Endocrinology 154 167-175.

McCall MA, Gregg RG, Behringer RR, Brenner M, Delaney CL, Galbreath EJ, Zhan, CL, Pearce RA, Chiu SY \& Messing A 1996 Targeted deletion in astrocyte intermediate filament (Gfap) alters neuronal physiology. PNAS 93 6361-6366.

MacSweeney D, Timms P \& Johnson A 1978 Thyro-endocrine pathology, obstetric morbidity and schizophrenia: survey of a hundred families with a schizophrenic proband. Pyschological Medicine 8151. 
Man EB, Brown JF \& Serunian SA 1991 Maternal hypothyroxinemia: psychoneurological deficits of progeny. Annals of Clinical and Laboratory Science 21 227-239.

Millar LK, Wing DA, Leung AS, Koonings PP, Montoro MN \& Mestman JH 1994 Low birth weight and preeclampsia in pregnancies complicated by hyperthyroidism. Obstetrics and Gynecology 84 946-949.

Morreale de Escobar G, Calvo R, Obregon MJ \& Escobar del Rey F 1992 Homeostasis of brain T3 in rat fetuses and their mothers: effects of thyroid status and iodine deficiency. Acta Medica Austriaca 19 (Suppl) 110-116.

Morreale de Escobar G, Calvo R, Escobar del Rey F \& Obregon MJ 1993 Differential effects of thyroid hormones on growth and thyrotropic hormones in rat fetuses near term. Endocrinology 132 2506-2564.

Morreale de Escobar G, Obregon MJ, Calvo R, Pedraza P \& Escobar del Rey F 1997 Iodine deficiency, the hidden scourge: the rat model of human neurological cretinism. In Recent Research and Development in Neuroendocrinology - Thyroid Hormone and Brain Maturation, pp 55-70. Ed. CE Hendrich. Trivandrum, India: Research Signpost.

Pickard MR, Sinha AK, Ogilvie L \& Ekins RP 1993 The influence of the maternal thyroid hormone environment during pregnancy on the ontogenesis of brain and placental ornithine decarboxylase activity in the rat. Journal of Endocrinology 139 205-212.

Pickard MR, Evans IM, Bandopadhyay R, Leonard AJ, Sinha AK \& Ekins RP 1997 Thyroid hormone action in rat brain from fetal to adult life. In Recent Research Developments in Neuroendocrinology Thyroid Hormone and Brain Maturation, pp 15-29. Ed. CE Hendrich. Trivandrum, India: Research Signpost.

Pickard MR, Sinha AK, Ogilvie LM, Leonard AJ, Edwards PR \& Ekins RP 1999 Maternal hypothyroxinemia influences glucose transporter expression in fetal brain and placenta. Journal of Endocrinology 163 385-394.

Pollin W, Stabenau JR, Mosher L \& Tupin J 1966 Life history differences in identical twins discordant for schizophrenia. American Journal of Orthopsychiatry 36492.

Pop VJ, Kuijpens JL, van Baar AL, Verkerk G, van Son MM, de Vijlder JJ, Vulsma T, Wiersinga WM, Drexhage HA \&
Vader HL 1999 Low maternal free thyroxine concentrations during early pregnancy are associated with impaired psychomotor development in infancy. Clinical Endocrinology 50 149-155.

Porterfield SP \& Hendrich CE 1991 The thyroidectomized pregnant rat - an animal model to study fetal effects of maternal hypothyroidism. Advances in Experimental Medicine and Biology 299 107-132.

Porterfield SP \& Hendrich CE 1993 The role of thyroid hormones in prenatal and neonatal neurological development - current perspectives. Endocrine Reviews 14 94-106.

Rahaman SO, Ghosh S, Mandal SK \& Sarkar PK 2000 Reduced expression and altered distribution of neurofilaments in neurons cultured in thyroid hormone-deficient medium. NeuroReport 11 $2717-2722$.

Ruiz de Ona C, Obregón MJ, Escobar del Rey F \& Morreale de Escobar G 1988 Developmental changes in rat brain 5'-deiodinase and thyroid hormones during the fetal period: the effects of fetal hypothyroidism and maternal thyroid hormones. Pediatric Research 24 588-594.

Sampson D, Pickard MR, Sinha AK, Evans IM, Leonard AJ \& Ekins RP 2000 Maternal thyroid status regulates the expression of neuronal and astrocytic cytoskeletal proteins in the fetal brain. Journal of Endocrinology 167 439-445.

Sampson D, Pickard MR, Leonard AJ, Evans IM, Sinha AK \& Ekins RP 2001 Thyroid hormone regulation of $\alpha$-internexin expression during early neuronal differentiation. Endocrine Abstracts 1 P218.

Sampson D, Pickard M, Evans I, Leonard A, Sinha A \& Ekins R 2002 Thyroid hormone regulates the expression of $\alpha$-internexin in neurones in culture. NeuroReport 13 273-276.

Schwartz HL, Ross ME \& Oppenheimer JH 1997 Lack of effect of thyroid hormone on late fetal rat brain development. Endocrinology 138 3119-3124.

Spencer GSG \& Robinson GM 1993 Stimulation of placental, fetal and neonatal growth by thyroxine administration to pregnant rats. Journal of Endocrinology 139 275-279.

Received in final form 28 August 2002

Accepted 5 September 2002 